Postprint Version 1.0

Journal website http://www.blackwell-synergy.com

Pubmed link http://www.ncbi.nlm.nih.gov/entrez/query.fcgi?cmd=Retrieve\&db=pubmed\&dop $\underline{\mathrm{t}=\text { Abstract \&list uids=12823428\&query } \mathrm{hl}=7 \& \text { itool=pubmed docsum }}$

DOI 10.1046/j.1365-2524.2003.00424.x

Correspondence: Marco Algera; NIVEL; PO Box 1568; 3500 BN Utrecht; The Netherlands; E-mail: m.algera@filternet.nl

\title{
An evaluation of the new home-care needs assessment policy in the Netherlands
}

\author{
Marco Algera mnsc rn, AnNeKe L. Francke rn, AdA KerKstra PhD AND JouKe VAN Der ZeE PhD \\ Netherlands Institute for Health Services Research (NIVEL), Utrecht, the Netherlands
}

\begin{abstract}
The aim of the present study was to describe the realisation of the new-style needs assessment in the Netherlands and how it is evaluated. Furthermore, judgements about the new way of assessing (chronic) patients' needs with respect to home care are presented. Data were gathered by means of a postal survey of all assessment agencies, home-care organisations and health insurers. The new-style assessment, as regulated by the Needs Assessment Decree, implies that home-care needs should be objectively assessed independently of the availability of care supply and integrally with other types of (longterm) care. This study shows that all the organisational structures required to realise these goals are present. However, according to factual and evaluative data, many practical aspects of these structures appear to be deficient. The national assessment forms, an instrument for gaining objectivity, are judged impracticable by half of the assessment agencies. Mandating arrangements threaten independent as well as integral needs assessment. Whether the new-style assessment is evaluated positively or negatively depends upon the type of organisation under study. On the one hand, assessment agencies are positive about their achievements. On the other, home-care organisations are generally negative about the functioning and advantages of the new style of needs assessment. Health insurers' opinions are in between those of assessment agencies and home-care organisations.
\end{abstract}

\section{INTRODUCTION}

In the Netherlands, home-care needs were assessed and such care was subsequently delivered by the same home-care staff until 1998 (and still are in the UK and many other European countries) (Hutten \& Kerkstra 1996, Parry-Jones \& Soulsby 2001, Algera et al. 2002). For the purposes of the present paper 'needs assessment' is defined as the result of a formalised process of objectively determining the need for care, and subsequently prescribing adequate care according to type, content and extent (Nationale Raad voor de Volksgezondheid 1994). In this context, the needs for care concern patients' health-related care deficits.

In the Netherlands, professional home care consists of care concerning instrumental activities of daily life (i.e. domestic care or home help), care concerning activities of daily living (i.e. physical or personal care), technical nursing care and psychosocial care, all delivered by professionals at the patient's home (Hutten \& Kerkstra 1996). Since 1998, the assessment of home-care needs (and also the assessment of needs for care in nursing and elderly homes) has been separated from the delivery of 
such care. These needs assessments are now undertaken by independent assessment agencies (called Regionale Indicatie Organen in Dutch). This profound change was introduced by the Needs Assessment Decree (NAD; Ministry of Health 1997). In this paper, the present authors describe how the NAD has been operationalised and how it is evaluated by the organisations involved. The NAD describes some organisational aspects as well as the major objectives of the new style of assessment, where needs assessment has to be independent, objective and integral.

The NAD (Ministry of Health 1997) prescribes that municipalities are responsible for establishing and maintaining the independent assessment agencies. In the year 2000, there were 85 assessment agencies, which encompass all the regions within the Netherlands. According to the NAD, these assessment agencies are required to examine patients' need for home care and long-term care, i.e. care provided by nursing homes or homes for elderly people. Furthermore, assessments for individual care budgets, a budget with which patients may purchase the allocated care themselves, belong to the obligatory domain of assessment agencies. Since 2000, the domain of the assessment agencies expanded to include other types of care, such as residential care for people with intellectual, physical or sensory disabilities, as well as housing and mobility arrangements for outpatients with physical disabilities (Algera et al . 2002). Mental healthcare has been added to the domain in 2003. In addition, optional assessment fields (e.g. various kinds of welfare) are allowed.

The assessment agencies have to be independent, in that the assessment of care eligibility should not be dependent on the supply available; for instance, the availability of home care should not interfere with the outcome of the actual needs assessment. With regard to home care, an exception is made for assessments of singular (non-complex) home-care needs (e.g. a need for limited domestic care or for eye drops to be administered). In those cases, assessment agencies are allowed to either perform these assessments themselves or to mandate the actual needs assessment to home-care organisations (Ministry of Health 1997).

In addition, the NAD states that assessment agencies should assess patients' needs for home care and the above-mentioned types of care integrally. For example, this implies that home-care needs should no longer be assessed separately from the need for semi-residential care. Thus, innovative combinations of several types of care are made possible, while enhancing need-directed care provision. Previously, intake committees of home-care organisations, nursing homes and homes for elderly people only made assessments related to their 'own' type of care and they did not take into account other possible care requirements (Dijkstra 2001, Algera et al . 2002).

Furthermore, according to the NAD, assessments must be conducted objectively so that they are less dependent on the individual characteristics of the assessor or the patient (Ministry of Health 1997). The government did not insist on the use of nationally developed assessment forms, but did recommend their use to enhance objectivity. This would promote equality for all patients in determining their care needs.

It is required that the result of the needs assessment is documented in an assessment report. The topics to be covered by the assessment report are also outlined in the NAD. Assessment reports should specify, among other things, the type and amount of care needed, and the urgency with which the care is to be delivered.

The government considers the new independent assessment agencies to be central to the so-called 'care chain' (Ministry of Health 1997, Tweede Kamer der Staten-Generaal 1999). The care chain describes the route that patients have to follow in order to receive professional help for their needs for care. Figure 1 depicts this route.

After patients have made a request for care at the assessment agency's office, an assessor usually makes a home visit to determine the care needed (e.g. 'You need to be washed five times a week'). The resulting assessment report is sent to the health insurance company. The insurer is responsible for judging whether or not the claim for care is legitimate, i.e. reimbursable by law. Subsequently, the health insurer confirms the care entitlement. Eventually, the care provider most eligible to deliver the allocated care starts giving care to patients, initially based on the assessment report.

The assessment of home-care needs in the Netherlands is promoted as integral and independent, and seems to be rather unique. However, striving for improved objectivity by using standardised assessment forms is done in other European countries as well (Hutten \& Kerkstra 1996). Assessment of need for home care on the one hand and the delivery of such care on the other by separate organisations is usually not found in other countries, although in some, the general practitioner may be 
the assessor for home care (Hutten \& Kerkstra 1996). Furthermore, comprehensibility of assessments is not seen in most other Western countries (Parry-Jones \& Soulsby 2001). Therefore, it is interesting to share how the new-style needs assessment, particularly regarding home care, is realised in Dutch practice.

The assessment agencies have been in operation for some years now, and there is some descriptive research on how the new-style assessment is evaluated by assessment agencies themselves and by home-care organisations as the organisation that has to deliver the care recommended by the assessment agencies. From this research, it appears that home-care organisations tend to judge assessment agencies negatively because of bureaucracy, lack of uniformity and poor usability of assessment reports (Bureau voor Toegepaste Economische en Ruimtelijke Planning BV 1999). Now that the assessment agencies have been established for a number of years, the present authors investigated how they, on the one hand, and home-care organisations and health insurers, on the other, evaluate the new-style assessment, focusing on the field of home care. In particular, the authors studied how home-care organisations, as primary users of the assessment agencies' reports, judge the usability of those reports.

The purpose of the present paper is to explain how the new style of assessment is realised in practice and how it is evaluated by relevant organisations. In doing so, the following research questions are posed:

-In the Netherlands, is the needs assessment process realised in accordance with the main elements of the NAD regarding the goals to be attained, the contents of the assessment report and waiting times?

- How is the new-style needs assessment for home care judged by assessment agencies, home-care organisations and health insurers in comparison to the former method of needs assessment?

-According to home-care organisations, how usable are the assessment reports produced by assessment agencies in practice?

-Which organisational characteristics of assessment agencies and/or home-care organisations may be related to home-care organisations' judgements of assessment agencies?

Patients' judgements on the new style of assessment are included in other parts of the research project and will be reported elsewhere.

\section{SUBJECTS AND METHODS}

In May 2000, all 85 assessment agencies, all 114 homecare organisations and all 31 health insurers in the Netherlands were approached with a questionnaire. The response rate amongst these organisations has been high (92\%, 81\% and 74\%, respectively). Reasons for not responding were lack of time or lack of interest. Most questionnaires were completed by managers or members of staff. If answers on specific items were not given, or were unclear or inconsistent with scores on other items, the respondent was telephoned for clarification, thus reducing missing values and increasing the quality of the data. By doing so, virtually complete data sets of 78 assessment agencies, 92 home-care organisations and 23 health insurers were obtained.

\section{Instruments}

Three questionnaires were developed, one for each type of organisation. If possible, items in the three questionnaires were formulated identically in order to allow comparisons between the participating organisations. Each questionnaire referred to the role the organisation plays in the procedures concerning the new-style assessment, such as activities performed by these organisations, waiting times encountered and the usability of assessment reports. Also, background information and evaluations of the new-style assessment were gathered by means of the surveys. The questionnaires were judged for content validity by experts in the respective fields.

\section{Statistical analyses}

All data were entered in the SPSS statistical computer program, and frequencies and percentages were computed. In addition, a judgement scale was constructed. The judgement scale was based on evaluations by home-care organisations of the extent to which the newstyle assessment was considered to have become more independent, objective and integral, and to have led to more efficient, 
transparent, accessible assessment procedures, or to better correspondence between patients' care needs and subsequent assessment, all in comparison with the assessment 'old style'. This judgement scale had a Cronbach's alpha of 0.85 .

In almost half of the cases $(43 \%, n=40)$, a home-care organisation dealt with only one assessment agency, in which case the opinion of the home-care organisation could be attributed to that particular assessment agency. Judgements by home-care organisations dealing with two or more assessment agencies were excluded from analysis. A $t$-test showed that the number of assessment agencies a home-care organisation has to deal with has no influence on the direction of the judgement (positive or negative).

Then, by computing Pearson's correlations, the characteristics of the 40 assessment agencies which significantly influenced home-care organisations' judgements were detected while independent variables showing multi-collinearity were excluded. Subsequently, these significant variables were simultaneously entered in a regression analysis. Another regression analysis was performed to find the significant characteristics of (all 92) home-care organisations themselves which influenced their opinion about the new style of assessment.

\section{RESULTS}

\section{Needs assessment in practice versus the Needs Assessment Decree}

By establishing over 80 independent assessment agencies, the objective described in the NAD (Ministry of Health 1997) to obtain independence through separation of needs assessment from delivery of care has been realised. Most of the responding assessment agencies came into operation during the first half of 1998. Data collected from assessment agencies show that two out of three assessment agencies did not mandate the assessment of singular home-care needs (any more) in 2000. Nevertheless, $9 \%$ of the assessment agencies $(n=7)$ let the home-care organisations perform these assessments, whereas another $24 \%(n=19)$ have arrangements with liaison nurses to assess homecare needs in patients to be discharged from hospital. Conversely, three out of four home-care organisations have stated that they do not have anything to do with needs assessment anymore, while 24 home-care organisations (26\%) are performing the singular, non-complex needs assessments.

According to the NAD, some assessment fields are obligatory in order to facilitate the integral needs assessment, the second goal to be attained. Table 1 shows all the obligatory fields to be fully covered by the assessment agencies under study. Mandating assessments to home-care organisations does not exclude these assessments from the assessment agency's domain. During the survey, the number of compulsory fields of assessment has been enlarged, enriching the comprehensibility of the assessment with respect to expensive housing adjustments. This may be the reason that only $27 \%$ of the assessment agencies ( $n=21$ ) state that they are active in this field.

\section{[ TABLE 1 ]}

In addition to the obligatory assessment fields, there is a wide variety of other optional assessment fields for which assessment agencies may assess patients' need (see the 'Optional' section of Table 1). One-third to half of the assessment agencies reported they would expand their domain in near future in favour of outpatient facilities and inpatient care for people with physical, sensory or intellectual disability, respectively.

The third main goal of the new-style assessment concerns the objectivity of the assessment by making use of protocols. In the NAD, the utilisation of national assessment forms, either on paper or electronically, is recommended. The results show that most assessment agencies appear to use the recommended assessment forms either entirely $(45 \%, n=35)$ or partially $(41 \%, n=32)$. Half of the assessing home-care organisations do not use the national recommended assessment forms, but most of them $(62 \%, n=8)$ have based their own assessment forms on the national protocol, making some adjustments typical for the situation of that organisation.

The needs assessment process results in an assessment report; some details on the content of assessment reports are given in Table 2. In these reports, the type of care needed is always determined by the assessment agency, as is the frequency of care to be delivered. Most assessment agencies specify the duration of care to be delivered in the assessment reports $(92 \%, n=72)$ as well as the 
validity limit of the report (91\%, $n=71)$. However, it appears that other specific topics referred to in the NAD are not mentioned by every assessment agency (see Table 2). The less-frequently mentioned items concern the urgency with which care should be delivered, the expertise of the caregiver, a second-best option in case the care needed is not available, and margins within which the caregiver may expand the frequency or caring time per day or per week without the need for a reassessment by the assessment agency. By and large, mandated home-care organisations' assessment reports contain the same elements as those by assessment agencies.

\section{[ TABLE 2 ]}

\section{Judgements about the new style of needs assessment}

Table 3 contains the judgements by assessment agencies, home-care organisations and health insurers regarding the realisation of the main goals of the newstyle assessment. When comparing the new style of assessment with the former way of assessing needs by home-care organisations, almost all (over 95\%) assessment agencies feel the assessment has become more independent, objective and integral. As far as healthinsurer respondents could make comparisons, they agree with the opinions of assessment agencies, but to a lesser degree. However, on the topic of objectivity, a large proportion of the health insurers disagree with the respondents from assessment agencies. With regard to home-care organisations, no distinct pattern emerged: the number of respondents agreeing with the statements, disagreeing or not having a specific opinion are approximately equal.

\section{[ TABLE 3 ]}

Table 4 presents some opinions about other features of the new-style assessment. In the opinion of assessment agencies and health insurers who were able to compare both assessment styles, the correspondence between home-care needs and the assessment of these needs has improved, as did the transparency of the assessment procedure. Interestingly, respondents employed by home-care organisations strongly disagree with this viewpoint. The accessibility and efficiency of the assessment procedure have improved according to the assessment agencies, but home-care organisations and health insurers seem to (strongly) disagree. Of note is the large percentage of respondents from assessment agencies not agreeing or disagreeing with the latter statements.

\section{[ TABLE 4 ]}

When considering the evaluations by assessment agencies and home-care organisations, a certain pattern seems to emerge: the less confident assessment agencies are unsure about the benefits of the new style of assessment, and the more negative home-care organisations show themselves to be concerned with these aspects. In other words, negative attitudes by home-care organisations seem to be confirmed by assessment agencies' less-positive evaluations.

The pattern of positive assessment agencies, negative home-care organisations and health insurers somewhere in between also emerges when these organisations were asked about (dis)advantages of the new-style assessment. Out of the 78 assessment agencies under study, 81\% experience more advantages than disadvantages. The health insurers share this experience to a lesser extent $(48 \%, n=$ 11). However, $38 \%$ of the home-care organisations ( $n=33$ ) experience more drawbacks than benefits. It is noteworthy that, in addition to their negative evaluation, one-quarter of all responding home-care organisations do not see any gain from the new style of assessment at all. Furthermore, one-third of the health insurers do not express a specific opinion in this matter. Table 5 displays some drawbacks as experienced by assessment agencies and home-care organisations and health insurers. Negative evaluation is mostly related to introductory difficulties, like computer problems and feeling uncomfortable about the new way in which the needs assessment is modelled. Because of the establishment of the assessment agencies, there is more bureaucracy and the presence of an extra link within the route for patients to pursue (see Fig. 1). These objections were identified by home-care organisations to a greater extent than health insurers. Interestingly, approximately one-quarter of the assessment agencies themselves reported these disadvantages. The feeling that complementary assessment is needed when starting the actual care by the homecare organisation is especially 
recognised by home-care organisations ( $59 \%, n=54)$, and interestingly, by almost $25 \%$ of the assessment agencies $(n=18)$.

\section{[ TABLE 5 ]}

[ FIGURE 1]

\section{Usability of assessment reports}

It has already been reported that not all assessment agencies and mandated home-care organisations make use of the national recommended assessment forms as an instrument for obtaining an objective needs assessment. Out of those that do ( $n=67$ and $n=11$, respectively), 52\% ( $n=35$ ) and 73\% ( $n$ $=8$ ) of the assessment agencies and mandated home-care organisations evaluate them positively. Nevertheless, $48 \%$ and $27 \%$, respectively, of both types of assessing organisations find the national recommended assessment forms impractical for different reasons. The forms not being orderly, too extensive or open to multiple interpretations are some of the criticisms.

On average, the practicability of the assessment agencies' reports is evaluated by home-care organisations as mediocre. While most assessment agencies $(87 \%, n=68)$ think that they are producing usable (i.e. not too global) assessment reports, only $16 \%(n=14)$ of the home-care organisations who have to work with these reports seem to agree. Furthermore, $13 \%(n=11)$ of them regard the assessment agency's report as useless. Only about $20 \%(n=19)$ of all responding homecare organisations judge complementary assessment, generally, to be redundant. The others think that the assessment report is not practicable and/or that the period between the assessment and the actual care provision is too long, so that the home-care needs may have changed in the meantime. Table 6 shows that the boundary conditions described in assessment reports, such as the validity limit of the assessment report, the margins and the indicated urgency, are found by home-care organisations to be moderately to highly practicable.

\section{[ TABLE 6 ]}

\section{Characteristics of influence on home-care organisations' judgements of new style of assessment}

By computing Pearson's correlations between the characteristics of assessment agencies and the judgement scale for home-care organisations, five significant independent variables have been identified (the direction of their correlation to a more positive evaluation is shown in brackets). The first four significant variables are: 'length of operational period of assessment agency' (longer); 'number of assessors (FTE)' (larger); 'number of assessment fields (magnitude of the assessment agency's domain)' (larger); and 'electronic exchangeability of assessment data between assessment agency and home-care organisation' (possible). The fifth significant variable is 'presence of hardware/software problems in assessment agencies' (absent), but because of collinearity with other significant variables, this variable has been excluded from further analysis. Table 7 shows the computed correlations.

\section{[ TABLE 7 ]}

Subsequently, the remaining four significant variables have been entered in a regression analysis (method Enter). The regression model built on the four independent variables proved to be significant ( $P=0.012$ ); the percentage of variance explained was $37.9 \%$. Out of the individual composing variables in the regression model, only the magnitude of the domain of the assessment agencies turned out to be significant ( $P=0.011$ ), i.e. in general, the more assessment fields an assessment agency integrates in assessing patients' care needs, the more positive the home-care organisations' judgement of the assessment agency.

The comparable regression model built on the characteristics data of home-care organisations has yielded no significant variables of home-care organisations which can be related to their scores on the judgement scale. 


\section{DISCUSSION}

The present study suggests that, by and large, the newstyle assessment is organised in accordance with what is regulated by law (the NAD; Ministry of Health 1997), and that all structures to attain the three main objectives of the new style assessment $Đ$ independent, integral and objective needs assessment $Đ$ seem to be present. However, the organisations involved hold different opinions about the new-style assessment and its practical consequences.

The first objective of the NAD, independent needs assessment, seems to have been attained. Over 80 regional assessment agencies have been established, the assessment of home-care needs is no longer an activity undertaken by care providers. This facilitates a needs assessment that is independent from the supply available and from the interests of care providers. However, with respect to singular, i.e. non-complex homecare needs, the NAD allowed for assessment agencies to give a mandate to homecare organisations to perform the assessment of this kind of need. The data show that about onequarter of the home-care organisations are assessing singular care needs, which is possibly threatening the independence of the assessment.

The second goal to be attained by the NAD, the integral needs assessment, also seems to be realised. Assessment agencies are carrying out needs assessments leading to home care, admission to a nursing home or a home for the elderly, or to individual care budgets. After the data collection was completed, the obligatory domain of assessment agencies was expanded and will continue to expand.

Furthermore, there are a wide variety of optional assessment fields which may enhance integral needs assessment. However, it is still unknown whether assessments actually have become more integral.

By recommending the use of national assessment forms, the NAD (Ministry of Health 1997) promoted its third goal, i.e. the objectivity of the needs assessment. From this study, the present authors conclude that the complete or partial use of these forms appears to be reasonably widespread amongst assessment agencies as well as, although less so, amongst mandated home-care organisations. The fact that assessment software is based on the national assessment protocol, but does not cover it completely, probably accounts for the relatively high score (41\%) on the partial use of these forms. About half of the mandated home-care organisations were not using the recommended assessment forms, but this does not necessarily imply that they would not assess objectively. They just do not use a certain tool with which objectivity may be achieved.

In addition, the results show that a substantial proportion of the assessment agencies which do use the national recommended assessment forms find them impracticable. Moreover, only a minority of the homecare organisations consider the product of assessment agencies, i.e. the assessment report, to be usable. A large majority of home-care organisations (as well as about $25 \%$ of the assessment agencies themselves) feel complementary assessment is necessary when starting the delivery of care. Whether or not this is a negative evaluation of the assessment agency's work depends on the validity of the expectancy of the home-care organisations. In other words, although the NAD prescribes some specific elements of the assessment reports, it is not predetermined that the assessment report should be usable as a detailed care plan. However, it should be noted that the home-care organisations' respondents (i.e. managers and staff members) may not be in the best position to judge the practical usability of assessment forms nor the resulting reports, because they are usually not the people working with these materials in practice. On the other hand, criticism of home helps or nurses about the usability of the assessment reports will reach their superiors.

As stated earlier, the independence of the needs assessment may be threatened by mandating arrangements, since assessment and care provision then come together in one organisation, as before (Dijkstra 2001, Algera et al . 2002). In addition, giving a mandate may threaten the integral needs assessment because assessors of home-care organisations will not have the necessary skills to comprehensively assess needs.

Conditions for independent or integral needs assessment will be hampered by mandating arrangements. However, bureaucracy in assessing needs, a problem well recognised by home-care organisations and health insurers, may be reduced, because the care chain can be shortened for noncomplex home-care needs.

The result of the assessment is not so much dependent on the patient's physical or psychological condition, but instead, focuses more on aspects such as living circumstances, which are hard to objectify (Dijkstra 2001). Furthermore, J.rg (2003) found that how the assessor and the patient get along with each other to be an influential factor on the eventual assessment. As a consequence, the 
inter-rater reliability among assessors is questionable (Schrijvers 2001, Jörg 2003). Therefore, equality in handling comparable care demands is not brought about structurally. Moreover, in many cases, the assessment reports do not contain all elements required by the NAD, leaving the care provider to fill in the gaps as considered convenient.

The evaluation by organisations dealing with the new-style assessment has given additional insight into the functioning of the assessment agencies. There is a hierarchy in judgements: the assessment agencies are more positive about the new style of assessment than the health insurers, who, in turn, appear to be more positive than home-care organisations. Assessment agencies consider the new-style assessment to be more independent, more objective and more comprehensive than the 'old style' assessment, i.e. care providers assessing patients' needs themselves. Furthermore, they hold the opinion that, in comparison with the former way of assessing home-care needs, the new style of assessment yields a better correspondence between home-care needs and assessment. The transparency, accessibility and efficiency have all improved according to assessment agencies, although the percentages of respondents agreeing nor disagreeing are noteworthy with regard to the latter two aspects.

The attitudes of assessment agencies and home-care organisations may not be very surprising. Because assessment agencies have interests in evaluating their own work and reason for existence positively, and homecare organisations probably have interests in trying to regain the authority of needs assessment, this may have strongly affected their responses. Of course, it may be possible that the realisation is as adequate as the assessment agencies claim it to be or has as many shortcomings as home-care organisations evaluate it to have. Possibly, because of their strategically more neutral position, the opinions of the health insurers may be considered as closer to the actual functioning of the newstyle assessment. If that is the case, it may be concluded that the assessment has become more independent and comprehensive, while the increase of objectivity is questionable. Furthermore, the assessment procedures have become more transparent, while they did not gain in efficiency or accessibility, according to health insurers.

Some negative opinions of assessment agencies, home-care organisations and health insurers may stem from the tumultuous environment in which these organisations have to maintain themselves. They all have to constantly cope with new regulations, which impedes consolidation (Bakker 2001, Schrijvers 2001). In addition, it may be concluded that the home-care organisations' criticism has barely changed over time, although the assessment agencies have increasingly matured in the meantime (Schrijvers 2001). In 1999, the same objections by home-care organisations to the new style assessment were observed (Bureau voor Toegepaste Economische en Ruimtelijke Planning BV 1999).

The result that the home-care organisations' positive judgements may be correlated to the assessment agency's larger domain is remarkable. It is not easily explained why the home-care organisations' attitude would become more positive if the assessment agency also assesses for other types of care not or only remotely related to home care. In addition, it was found that no characteristics of home-care organisations themselves could be related to their opinion about the new style assessment. Therefore, it may be concluded that, for policy makers, there are no specific attention areas located in either assessment agencies or home-care organisations to improve the latters' judgements about the new procedures concerning the assessment for home care.

In the present paper, only evaluations of relevant organisations were included. Patients' perspectives on the new-style assessment were part of the evaluation, but these results will be reported elsewhere.

The overall conclusion is that, in principle, the way in which the new style of assessment has been constructed in the Netherlands is conditionally adequate for independent, integral and objective needs assessment in home care. This is more than can be observed regarding the needs-led assessment in the UK (Parry- Jones \& Soulsby 2001). However, in the Netherlands, the practical realisation of the new structures still needs to be refined. This will possibly improve the quality of the product of assessment agencies and smooth the route patients that have to travel from presenting their care demand to receiving the allocated care.

\section{ACKNOWLEDGEMENTS}

This research project was funded by NWO-ZOB (Netherlands Organisation of Scientific Research, Research Programme on Care and Social Support for Chronically Ill Patients), the Netherlands. 
Algera, M., Francke, A.L., Kerkstra, A., Zee, J. van der

An evaluation of the new home-care needs assessment policy in the Netherlands.

Health and Social Care in the Community: 11, 2003, nr. 3, p. 232-241

\section{TABLES}

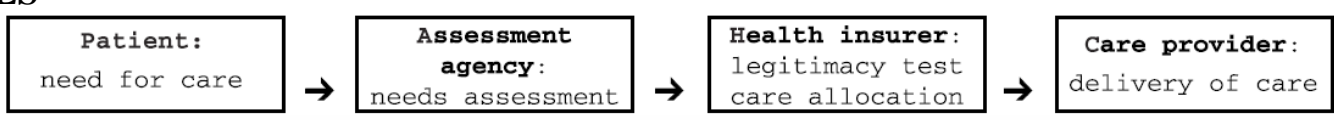

Figure 1 Care chain showing the route that patients have to follow in order to receive professional help for their care needs.

Table 1 Domain of needs assessment by assessment agencies $(n=78)^{*}$

\begin{tabular}{lll}
\hline Domain of needs assessment & Number & Percentage \\
\hline Compulsory & & \\
Nursing home & 78 & 100 \\
Home for the elderly & 78 & 100 \\
Home care: & & \\
$\quad$ singular needs & 78 & 100 \\
$\quad$ complex needs & 78 & 100 \\
Individual care budget & 77 & 99 \\
Expensive housing adjustments & 21 & 27 \\
Optional & & \\
Day care/night care & 76 & 97 \\
Sheltered home & 43 & 55 \\
Meals on wheels & 32 & 41 \\
Arousing public awareness & 31 & 40 \\
Other facilities for people with disabilities & 30 & 39 \\
Less-expensive housing adjustments & 29 & 37 \\
Nursing aids & 26 & 33 \\
Supplementary public transport & 19 & 24 \\
\hline
\end{tabular}

* Multiple responses allowed.

Table 2 Elements of assessment reports determined by assessment agencies $(n=78)$ and mandated home-care organisations $(n=24)^{*}$

\begin{tabular}{|c|c|c|c|c|}
\hline \multirow[b]{2}{*}{ Element } & \multicolumn{2}{|c|}{ Assessment agency } & \multicolumn{2}{|c|}{ Mandated home-care organisation } \\
\hline & Number & Percentage & Number & Percentage \\
\hline Type of care & 78 & 100 & 20 & 95 \\
\hline Frequency of care to be delivered & 77 & 99 & 19 & 91 \\
\hline Duration of care to be delivered & 72 & 92 & 20 & 95 \\
\hline Validity limit of assessment report & 71 & 91 & $-\dagger$ & $-\dagger$ \\
\hline Urgency & 69 & 89 & $-\dagger$ & $-\dagger$ \\
\hline Level of expertise of caregiver & 59 & 76 & 17 & 81 \\
\hline Second-best option & 48 & 62 & $-\dagger$ & $-\dagger$ \\
\hline Margins of expanding frequency or amount of care & 38 & 49 & $-\dagger$ & $-\dagger$ \\
\hline
\end{tabular}

* Multiple responses allowed.

+ In the home-care organisations' questionnaire, not all the options could be selected; these options seemed less relevant because of the mandating arrangement and the non-complexity of the care needs to be assessed by the mandated home-care organisations. 
Algera, M., Francke, A.L., Kerkstra, A., Zee, J. van der

An evaluation of the new home-care needs assessment policy in the Netherlands.

Health and Social Care in the Community: 11, 2003, nr. 3, p. 232-241

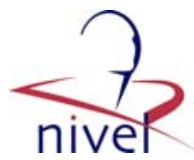

\begin{tabular}{|c|c|c|c|}
\hline \multirow[b]{2}{*}{ Goal new-style needs assessment } & \multicolumn{3}{|l|}{ Percentage } \\
\hline & $\begin{array}{l}\text { Assessment } \\
\text { agency }\end{array}$ & $\begin{array}{l}\text { Home-care } \\
\text { organisation }\end{array}$ & $\begin{array}{l}\text { Health } \\
\text { insurer }\end{array}$ \\
\hline Assessment became more objective: & & & $23^{*}$ \\
\hline (totally) agree & 95 & 31 & 36 \\
\hline neither agree nor disagree & 4 & 26 & 0 \\
\hline (totally) disagree & 1 & 42 & 41 \\
\hline Assessment became more independent: & & & $13^{*}$ \\
\hline (totally) agree & 99 & 42 & 48 \\
\hline neither agree nor disagree & 0 & 26 & 17 \\
\hline (totally) disagree & 1 & 32 & 22 \\
\hline Assessment became more comprehensive: & & & $22^{*}$ \\
\hline (totally) agree & 96 & 32 & 70 \\
\hline neither agree nor disagree & 1 & 29 & 0 \\
\hline (totally) disagree & 3 & 39 & 9 \\
\hline
\end{tabular}

Table 3 Judgements by assessment agencies $(n=78)$, home-care organisations $(n=92)$ and health insurers $(n=23)$ about goal attainment according to the Needs Assessment Decree

* In these cases, it was not possible for respondents of health insurers to compare the new-style assessment with the old-style assessment, probably because they had no experience with the old-style assessment.

Table 4 Judgements by assessment agencies $(n=78)$, home-care organisations $(n=92)$ and health insurers $(n=23)$ of new-style assessment compared to the old style of needs assessment

\begin{tabular}{|c|c|c|c|}
\hline \multirow[b]{2}{*}{ Characteristic } & \multicolumn{3}{|l|}{ Percentage } \\
\hline & $\begin{array}{l}\text { Assessment } \\
\text { agency }\end{array}$ & $\begin{array}{l}\text { Home-care } \\
\text { organisation }\end{array}$ & $\begin{array}{l}\text { Health } \\
\text { insurer }\end{array}$ \\
\hline Better correspondence assessment and home-care needs: & & & $52^{*}$ \\
\hline (totally) agree & 82 & 9 & 30 \\
\hline neither agree nor disagree & 17 & 22 & 4 \\
\hline (totally) disagree & 1 & 69 & 13 \\
\hline Assessment more transparent: & & & $9^{*}$ \\
\hline (totally) agree & 67 & 15 & 59 \\
\hline neither agree nor disagree & 18 & 19 & 14 \\
\hline (totally) disagree & 15 & 66 & 18 \\
\hline Accessibility assessment improved: & & & $39^{*}$ \\
\hline (totally) agree & 47 & 9 & 17 \\
\hline neither agree nor disagree & 35 & 19 & 13 \\
\hline (totally) disagree & 18 & 72 & 30 \\
\hline Assessment more efficient: & & & $50^{*}$ \\
\hline (totally) agree & 48 & 7 & 5 \\
\hline neither agree nor disagree & 46 & 13 & 15 \\
\hline (totally) disagree & 7 & 81 & 30 \\
\hline
\end{tabular}

* In these cases, it was not possible for respondents of health insurers to compare the new-style assessment with the old-style assessment, probably because they had no experience with the old-style assessment. assessment as judged by assessment agencies $(n=78)$, home-care organisations $(n=92)$ and health insurers $(n=23)^{\star}$
Table 5 Disadvantages of new-style

\begin{tabular}{llll}
\hline & Percentage & & \\
\cline { 2 - 4 } Disadvantage & $\begin{array}{l}\text { Assessment } \\
\text { agency }\end{array}$ & $\begin{array}{l}\text { Home-care } \\
\text { organisation }\end{array}$ & $\begin{array}{l}\text { Health } \\
\text { insurer }\end{array}$ \\
\hline Introductory problems & 58 & 66 & 78 \\
More bureaucracy & 22 & 92 & 61 \\
Extra link in patient's route & 28 & 72 & 30 \\
Complementary assessment needed & 24 & 61 & $-\dagger$ \\
\hline
\end{tabular}

* Multiple responses allowed.

+ Not asked.

\begin{tabular}{llll}
\hline & \multicolumn{2}{l}{ Evaluation (\%) } \\
\cline { 2 - 4 } Characteristic & High & Moderate & Low \\
\hline Practicability of the validity limit of the assessment report & 40 & 47 & 14 \\
Practicability of margins within the assessment report & 53 & 32 & 15 \\
Practicability of indicated urgency in the assessment report & 35 & 42 & 24 \\
\hline
\end{tabular}

Table 6 Home-care organisations' evaluation of the usability of assessment agencies' reports $(n=92)$ 
Algera, M., Francke, A.L., Kerkstra, A., Zee, J. van der

An evaluation of the new home-care needs assessment policy in the Netherlands.

Health and Social Care in the Community: 11, 2003, nr. 3, p. 232-241

Table 7 Correlations between assessment agencies' characteristics and judgements by home-care organisations, and results of regression analysis $(n=40)$

\begin{tabular}{|c|c|c|c|c|c|}
\hline \multirow[b]{2}{*}{$\begin{array}{l}\text { Assessment agency's } \\
\text { characteristic }\end{array}$} & \multicolumn{2}{|c|}{$\begin{array}{l}\text { Correlation with } \\
\text { home-care organisation's } \\
\text { score on judgement scale }\end{array}$} & \multicolumn{3}{|l|}{ Regression model } \\
\hline & Pearsons' $R$ & $P$-value & $\begin{array}{l}\text { Unstandardised } \\
\text { coefficient }\end{array}$ & $\begin{array}{l}\text { Standardised } \\
\text { coefficient }\end{array}$ & $P$-value \\
\hline & & & Constant $=0.846$ & - & 0.244 \\
\hline Length of operational period & -0.311 & 0.026 & -0.06105 & -0.078 & 0.64 \\
\hline Number of assessors (FTE) & 0.291 & 0.036 & 0.009525 & 0.183 & 0.26 \\
\hline Number of assessment fields & 0.372 & 0.009 & 0.106 & 0.434 & 0.011 \\
\hline Electronic exchangeability of data & 0.399 & 0.012 & 0.418 & 0.276 & 0.098 \\
\hline
\end{tabular}

\section{REFERENCES}

Algera M., Francke A.L. \& Van der Zee J. (2002) Zorgindicatiestelling 'nieuwe stijl' binnen de zorgketen; een literatuurstudie naar de haalbaarheid van de doelstellingen van de indicatiestelling 'nieuwe stijl' en de realisering van de zorgketen. (New-style needs assessment within the care chain: a literature study on the feasibility of the goals of the new-style assessment and the realisation of the care chain.) Verpleegkunde Nederlands-vlaams Wetenschappelijk Tijdschrift voor Verpleegkundigen $17,140 Đ 151$.

Bakker P.F. (2001) Periodieke inventarisatie indicatie-organen; stand van zaken augustus 2001.

(Periodic Inventory Assessment Agencies: The State of Affairs in August 2001.) Hoeksma, Homans \& Menting, Enschede.

Bureau voor Toegepaste Economische en Ruimtelijke Planning BV (1999) Uitwerking enquête Landelijke Vereniging voor Thuiszorg; naar de effecten van de overheveling van de indicatiestelling. (Results of a Survey by the National Association for Home Care: On the Effects of the Transfer of the Needs Assessment.) Bureau voor Toegepaste Economische en Ruimtelijke Planning BV, Amersfoort.

Dijkstra G.J. (2001) De indicatiestelling voor verzorgingshuizen en verpleeghuizen. (Needs Assessment in Homes for the Elderly and Nursing Homes.) Rijksuniversiteit Groningen, Groningen.

Hutten J.B.F. \& Kerkstra A. (1996) Home Care in Europe: A Country-specific Guide to its Organization and Financing. Ashgate Publishing, Aldershot.

Jörg F. (2003) Objectivity in Individual Needs Assessment for Access to Long-term Care. University of Utrecht, Utrecht.

Ministry of Health (1997) Zorgindicatiebesluit (Decree of 2 October 1997, regarding field of activities, the formation and the operation procedures of Regional Needs Assessment Agencies.) Staatsblad van het Koninkrijk der Nederlanden 447. Staatsuitgeverij, 's-Gravenhage.

Nationale Raad voor de Volksgezondheid (1994) Indicatiestelling en zorg op maat; advies van de Nationale Raad voor de Volksgezondheid en het College voor Ziekenhuisvoorzieningen. (Needs Assessment and Customised Care: Recommendations by the National Council for Public Health and the Council for Hospital Facilities.) Nationale Raad voor de Volksgezondheid, Zoetermeer.

Parry-Jones B. \& Soulsby J. (2001) Needs-led assessment: the challenges and the reality. Health and Social Care in the Community 9, 414Đ428.

Schrijvers A.J.P. (2001) RIO, het jongste kind groeit op; eindrapport van de evaluatie van het Zorgindicatiebes/uit van 1998. (The Assessment Agency, the Youngest Child Grows to Maturity. Final Report on the Evaluation of the Needs Assessment Decree of 1998.) Julius Centrum voor Huisartsgeneeskunde en Patiëntgebonden onderzoek, Utrecht.

Tweede Kamer der Staten-Generaal (1999) Nota Zicht op Zorg; Plan van aanpak modernisering AWBZ. (Note Vision on Care: Approach Modernising the Exceptional Medical Expenses Act.) Tweede Kamer vergaderjaar 1998Đ1999, 26.631. Staatsuitgeverij, "s-Gravenhage. 